\title{
A aprendizagem coletiva de língua portuguesa para surdos através das interações em língua de sinais
}

Collective Learning of the Portuguese Language for the Deaf Through Interactions in sign Language

Vanessa de Oliveira Dagostim Pires*

Universidade do Vale do Rio dos Sinos

São Leopoldo - Rio Grande do Sul / Brasil

RESUMO: Este artigo analisa as interações em língua de sinais (LS), entre alunos surdos do ensino fundamental, nas aulas de Língua Portuguesa. Ele foi inspirado no trabalho de Donato (1994), que buscou identificar a presença da prática do andaimento nas interações entre pares em sala de aula de língua francesa como segunda língua. Em nossa pesquisa, analisamos através do sociointeracionismo (VYGOTSKY, 1988; WOOD, BRUNNER e ROSS, 1976) as interaçōes entre os alunos surdos durante o desenvolvimento de uma unidade didática que os incentivava a escrever uma carta de reclamação, em Língua Portuguesa, sobre a sua escola. É possível perceber como as estratégias de andaimento possibilitaram a construção coletiva de aprendizagem para a realização da tarefa proposta. PALAVRAS-CHAVE: Andaimento coletivo, Língua portuguesa para surdos, Educação de surdos, Sociointeracionismo.

ABSTRACT: This paper analyzes the interactions in sign language (SL) among deaf elementary school students in Portuguese language classes and was inspired by the work of Donato (1994), who sought to identify scaffolding practices in interactions among peers in French as a second language classes. Applying the social interactionist approach (Vygotsky, 1988; Wood, Brunner and Ross, 1976), the present research analyzed the interactions between deaf students during the development of a teaching unit that encouraged them to write a letter of complaint, in Portuguese, about their school. It is possible to perceive how the scaffolding strategies made the construction of collective learning to perform the proposed task possible.

KEYWORDS: Collective scaffolding, Portuguese language for the deaf, Deaf education, Social interactionist theory.

*vanessadagostim@gmail.com 


\section{INTRODUÇÃO}

O presente artigo apresenta um recorte de uma pesquisa maior, intitulada "Andaimento coletivo como prática de ensino-aprendizagem de língua portuguesa para surdos" (PIRES, 2009), que analisou as interaçōes em língua de sinais (LS), entre alunos surdos do ensino fundamental, nas aulas de Língua Portuguesa (LP), em uma escola especial para surdos na região metropolitana de Porto Alegre, do sistema público de ensino. A pesquisa inspirou-se no trabalho de Donato (1994), que buscou identificar a presença da prática do andaimento nas interações entre pares em sala de aula de língua francesa como segunda língua. Em nossa pesquisa analisamos, através do sociointeracionismo (VYGOTSKY, 1988; WOOD, BRUNNER \& ROSS, 1976), as interações entre os alunos surdos durante o desenvolvimento de uma unidade didática que os incentivava a escrever uma carta de reclamação, em Língua Portuguesa, sobre a sua escola.

As perguntas que nortearam a pesquisa foram: "Como se dá a coconstrução de aprendizagem de língua numa classe de Língua Portuguesa para surdos (LP/S)?"; "Qual a relação entre a mediação entre pares e a internalização de certas regras gramaticais da LP?"; "Como as práticas de atividades em conjunto geram estratégias facilitadoras de aprendizagem de LP?" Para realizar a análise dos dados gerados de modo a percorrer o caminho proposto neste trabalho, utilizaremos como uma das metodologias a organização da fala-em-interaçãao entre os sujeitos observados. A atividade de produção da carta de reclamação foi desenvolvida em trios. Através da transcrição e da análise dos dados, foi possível perceber como as estratégias de andaimento possibilitaram a construção coletiva de aprendizagem para a realização da tarefa proposta, apontando caminhos interessantes para educadores e pesquisadores do letramento de surdos.

\footnotetext{
${ }^{1}$ O termo fala-em-interação será mantido, mesmo que nossos dados não sejam produzidos em Língua Oral (LO), mas em LS, pois utilizamos o termo "fala" segundo o conceito compilado por Garcez e Ostermann (2002, p.262): "qualquer produção de elocuções em situação de interlocução". No contexto investigado, as elocuções serão produzidas, basicamente, em dois códigos: Libras - principalmente - e Língua Portuguesa, alternada ou simultaneamente, em alguns momentos.
} 


\section{O CONTEXTO DE ENSINO E APRENDIZAGEM DE LP/S}

A educação de surdos no Brasil, assim como nosso sistema educativo em geral, segue tendências mundiais de educação, discutidas em eventos e convençōes internacionais sobre as teorias e metodologias de ensino. Como bem afirmam Lacerda e Lodi (2009), essa história foi marcada, em todo o tempo, por conflitos e controvérsias em torno da oralização e da língua própria dos surdos. Nas palavras das autoras,

o foco dos debates sempre esteve relacionado a questōes linguísticas, ou seja, se os surdos deveriam desenvolver a linguagem oral (acompanhada ou não de sinais) e, assim, sua educação deveria ser realizada e pensada a partir da língua utilizada pelos ouvintes; ou se deveria ser permitido a eles o uso da língua de sinais, cujo reflexo seria também sentido nas esferas educacionais (LACERDA e LODI, 2009, p.11).

Retomando esse histórico, ${ }^{2}$ parto de 1880 , com a ocorrência da imposição da educação oralista para surdos, no Congresso de Milão. Acreditava-se, então, que o indivíduo surdo só poderia ser educado formalmente se fosse capaz de falar oralmente. O papel principal da escola era o desenvolvimento dessa fala, primordialmente. Para que os métodos fonoarticulatórios impostos tivessem sucesso, era preciso que qualquer tipo de comunicação gestual fosse abolida. Foi proibido, por essa razão, o uso das línguas de sinais em espaços institucionais. As línguas de sinais foram marginalizadas e ficaram renegadas ao uso caseiro, aos encontros "secretos" entre os surdos. Seu uso em sala de aula era visto como altamente maléfico à educação desses indivíduos.

Diante do fracasso do método oralista, pois ainda que aprendessem a oralizar, os surdos não se desenvolviam, nem linguisticamente, nem cognitivamente conforme o esperado, pesquisadores estadunidenses iniciaram os primeiros estudos relevantes, no contexto linguístico, sobre as línguas de sinais, especialmente a língua de sinais americana (ASL), nos anos 1960. Essa fase é marcada pelas publicações dos primeiros estudos de Stokoe, em 1960, que impulsionaram as pesquisas e, consequentemente, o reconhecimento de outras línguas de sinais. Em decorrência desses

\footnotetext{
${ }^{2}$ É importante esclarecer que a história de educação dos surdos no Brasil nasce bem antes de 1880, mas o objetivo desta seção é apenas focalizar alguns eventos relevantes para a presente discussão.
} 
estudos, que conferiram às línguas de sinais o status de "língua", e a partir da constatação do fracasso da educação oralista, a educação dos surdos começou um período denominado "Comunicação Total", com início por volta dos anos 1960, na Europa e nos Estados Unidos, e dos anos 1970 no Brasil. A Comunicação Total caracteriza-se pelo uso de vários métodos comunicativos, como gestos, palavras e mímicas na educação da criança surda, na tentativa de que ela adquira uma língua. Nesse período, foram criados sistemas de sinais artificiais ${ }^{3}$ para a comunicação com os surdos, como o Sistema de Sinais de Paget-Gorman (SSPG) ${ }^{4}$ e o Vocabulário Makaton ${ }^{5}$ (CAPOVILLA, 2000). Embora se tenha obtido avanços promissores com os estudantes surdos, os resultados esperados ainda eram muito pequenos, e a maioria dos surdos continuava enfrentando sérias dificuldades para comunicar-se e para aprender na escola. Estudiosos empenhados em descobrir qual era o motivo dessa ineficácia descobriram algo desconcertante, porém, inovador em relação às línguas de sinais: "[...] embora, por princípio, a comunicação total apoiasse o uso simultâneo da língua de sinais com sistemas de sinais, na prática, tal conciliação nunca foi e nem seria efetivamente possível, devido à natureza extremamente distinta da LS" (CAPOVILLA, 2000, p.10). Tal princípio também pode ser aplicado para ser entendida a impossibilidade de uma pessoa produzir, simultaneamente, a língua de sinais e a língua falada $\mathrm{em}^{6}$ sua totalidade.

\footnotetext{
${ }^{3}$ Os sistemas de sinais artificiais podem basear-se no vocabulário das línguas de sinais, aos quais são adicionados aspectos da língua falada ou, então, a adoção de um vocabulário artificial. A característica mais importante dos sistemas de sinais artificiais é a sequência da ordem de produção da língua falada, no qual são aplicados os sinais, simultaneamente à produção oral da língua falada. Sua desvantagem é, além de uma artificialidade semântica, o grande esforço dispensado pelo aprendiz, o que os converte em meios de comunicação insuficientes (CAPOVILLA, 2000).

${ }^{4}$ O SSPG é um sistema que adota um vocabulário totalmente artificial concebido para ajudar crianças na aprendizagem de língua escrita. Também é utilizado para crianças com severos distúrbios de aprendizagem, deficiência física e autismo. Seu uso atingiu o pico na década de 1970 (CAPOVILLA, 2000).

${ }^{5} \mathrm{O}$ vocabulário Makaton tem como objetivo dar suporte a crianças surdas com dificuldades de aprendizagem no desenvolvimento da linguagem (CAPOVILLA, 2000).

${ }^{6}$ Embora, ao se comunicarem em língua de sinais, alguns usuários pareçam oralizar algumas palavras, essa atitude não se caracteriza como oralização. Já existem estudos sobre essa prática em línguas de sinais do exterior, os quais a classificam em duas categorias: mouthing, balbucios relacionados à língua falada; e mouth gestures, outros movimentos dentro da articulação da língua. Vale lembrar que ambas são espontâneas
} 
O fracasso apresentado pelo método da comunicação total foi constatado na mesma época em que as pesquisas sobre as línguas de sinais eram aprofundadas, e assim, no início da década de 1980, as escolas de surdos começaram a adotar a abordagem educativa bilíngue, a qual entende que as línguas de sinais naturais das comunidades surdas podem ser o veículo principal de ensino aos surdos. No Brasil, a educação bilíngue de surdos começa a tomar força nos anos 1990, pouco depois das primeiras discussões relativas à educação das pessoas surdas e aos estudos linguísticos sobre a Libras, em meados dos anos 1980 (FERREIRA-BRITO, 1984). No entanto, somente em 2002 ocorre o reconhecimento legal da Libras no Brasil (por meio da Lei no 10.436/02), o que impulsiona o aumento de pesquisas envolvendo escolas de surdos e a valorização dessa língua.

A abordagem educativa bilíngue, ao reconhecer e introduzir as LS como línguas oficiais e naturais dos surdos na sala de aula, revolucionou a educação de surdos. Essa abordagem defende que o surdo seja educado, sempre que possível, em instituições específicas para surdos, bilíngues e biculturais, em que a Língua de Sinais seja a primeira língua da escola, objeto de análise e estudo linguístico e meio de acesso às informações e ensino das demais disciplinas. A Língua Portuguesa, nessas instituiçôes, assume a função de segunda língua, e é ensinada para que o surdo desenvolva as habilidades de escrita e leitura. Há também, nessas escolas, a possibilidade de que o aluno surdo seja alfabetizado, primeiramente, em língua de sinais, para, apenas depois, ser alfabetizado em língua portuguesa. Essa abordagem defende que o processo de alfabetização seja delineado a partir da descoberta da própria língua e das relações estabelecidas por meio da língua (QUADROS, 2000).

\section{LETRAMENTO DOS SURDOS EM LÍNGUA PORTUGUESA}

Alguns trabalhos têm se preocupado com o letramento dos surdos. Entre estes, destacamos a pesquisa realizada por Lodi (2004), pesquisadora brasileira, em sua tese de doutorado. A autora desenvolveu uma série de oficinas de leituras com um grupo de surdos adultos, usuários de Libras, com textos de diferentes gêneros discursivos, e percebeu que, para o grupo, não existia a noção de que Libras e Língua Portuguesa fossem línguas diferentes. Para eles, estas eram a mesma língua materializada mediante duas formas

e que seu uso não é sinônimo de comunicação total ou de português sinalizado (SUTTON-SPENCE, 2007). 
distintas. Também foi possível observar que grande parte da dificuldade de leitura em Língua Portuguesa evidenciada pelos participantes da pesquisa, que não tiveram uma educaçãoo bilíngue, ocorreu pela aquisição tardia da Libras e de todo o conhecimento de mundo que foi perdido até o momento dessa aquisição. Graças a esse fato a pesquisadora defende

a necessidade dos surdos serem imersos em situações de leitura significativas, que envolvam temas diversos desenvolvidos em gêneros discursivos variados. Deve-se considerar que a restrição quanto aos conhecimentos de mundo e quanto às interaçôes dialógicas com os diferentes temas são decorrentes da forma pela qual os sujeitos têm acesso a eles, ou seja, por meio de interações face a face estabelecidas por intermédio da linguagem oral (e, portanto, de difícil acesso a eles). (LODI, 2004, p.242)

As restrições quanto aos conhecimentos de mundo, citadas por Lodi (2004) no trecho anterior, decorrem do fato de a maioria das crianças surdas nascerem em lares ouvintes que desconhecem a língua de sinais. Nestes contextos, a interação entre a criança e a família ocorre a partir de sinais criados pelo próprio núcleo familiar que suprem a necessidade da comunicação básica, mas não tornam todas as narrativas acessíveis à criança surda. A respeito disso, Karnopp e Pereira (2010, p.35) contam que

o distanciamento das práticas de leitura e de escrita, somado a pouca ou nenhuma familiaridade com o português, resulta em alunos que sabem codificar e decodificar os símbolos gráficos, mas que não conseguem atribuir sentido ao que leem. [...] As crianças surdas, de famílias ouvintes, têm pouco acesso às conversas que ocorrem em casa, no dia a dia, assim como às narrativas de histórias que são passadas de gerações a geraçôes. Também as atividades que envolvem a leitura e a escrita, como contar histórias, são pouco utilizadas pelos familiares ouvintes de crianças surdas.

Outro fator que colabora para o pouco conhecimento de mundo, o que seria necessário para a atribuição de sentido à leitura, pode ser a oferta escassa de textos genuínos para os alunos surdos durante a educação básica. Soares (2010) diz que as duas condiçôes básicas para o desenvolvimento do letramento são a escolarização real e efetiva da população e a disponibilidade de material de leitura. Embora acredite que as duas condições são negligenciadas na educação dos surdos, neste trabalho me atenho ao segundo item. Karnopp e Pereira (2010) argumentam que, como os professores de 
surdos acreditam que seus alunos não possuem condições de ler textos longos ou considerados mais complexos, adaptam os textos ou os infantilizam para a realização das atividades de leitura. Assim, ocorre aquilo que Karnopp (2005) denuncia em sua pesquisa a respeito da leitura de surdos universitários: todos os surdos envolvidos em sua pesquisa estavam na primeira leitura de livros de suas vidas já na graduação. Durante o período de educação básica, aqueles nunca haviam sido convidados a ler um livro.

A escrita surda em LP também possui suas particularidades e é carente de atenção. Quando um ouvinte se depara pela primeira vez com uma produção escrita por um surdo, algumas "diferenças" podem chamar sua atenção, como a concordância de alguns verbos. Nascimento (2008), em uma pesquisa sobre a produção escrita de surdos universitários pernambucanos, fez um levantamento das inadequaçóes verbais, uma das dificuldades mais evidentes identificadas na produção escrita no corpus analisado pela autora. A pesquisadora classificou tais dificuldades como: omissão de verbos, sequências de verbos que fogem aos padrões sintáticos do português e verbos com status de nomes, inadequaçóes de flexões verbais e verbos com grafia atípica. De acordo com Nascimento (2008), essas dificuldades podem ser justificadas pela interferência da estrutura gramatical da Libras na LP e pelo desconhecimento do sistema fonológico da língua causado pela condição do surdo. Entretanto, é possível que a deficiência no letramento acadêmico dos surdos seja motivada por um problema mais complexo, que tem início na escolarização tardia do sujeito, na falta de comunicação com seu meio durante a infância e que percorre toda a sua vida escolar, e na falta de instituições e profissionais preparados para atendê-los de forma adequada.

Para compreender melhor o processo de escrita em LP dos aprendizes surdos, Silva (2001) analisou redaçôes de oito alunos surdos entre 16 e 21 anos, produzidas sem acompanhamento pedagógico em casa. Todos eram usuários de Libras. A título de exemplificação, algumas inadequações gramaticais recorrentes em textos de surdos e coletadas pela pesquisadora são listadas abaixo (SILVA, 2001): ${ }^{7}$

- Ser estudante não sabe nada. Fazer a palavra trocando tudo para coitado. Ser estudante foi acabar um ano de escola, depois foi passear na festa de discoteca. Acabando na festa até às 1 hs às noites. (p.72, Redação II).

\footnotetext{
${ }^{7}$ Grifo meu.

${ }^{8}$ Texto original: "Fezer a palavra trocando tudo para coitado".
} 
- Eu e Ronildo passearam na rua de noite dia do sábado. Wanderson e Ronildo fui conhecer as garotas na pracinha. Nos foram namorando muito na festa do show. (p.78, Redação IV).

- A família vamos viajam em Entre Rios Minas Gerais, meu avô é bom, outro primo vamos brincar rua. (p.82, Redação V).

Embora o presente estudo tenha um caráter essencialmente interacionista, reconhecemos que o processo de escrita também depende de fatores cognitivos do desenvolvimento do indivíduo. São diversos os pesquisadores deste campo de estudo que têm se dedicado a investigar outros métodos para a aquisição da escrita pelos surdos que, segundo eles, diminuiriam as dificuldades de escrita do sujeito surdo, conforme as apresentadas por Silva (2001). Capovilla e Capovilla (2004) justificam que há uma dificuldade crucial na lógica de aquisição de leitura e escrita alfabéticas. Segundo os autores, essa dificuldade reside no fato de o desenvolvimento cognitivo e linguístico pleno possibilitar à criança usar sua LS (como L1) como metalinguagem para a aquisição da leitura e da escrita, porém, estas duas habilidades são introduzidas, na vida do aluno, por meio da LP. A partir de estudos feitos em análises dos tipos de inadequações que a criança surda tende a cometer ao ler e ao escrever, os autores acima mencionados relatam que:

Tal análise revela que a escrita mapeia o processamento de informação na língua primária, que é a fala para a criança ouvinte e a LS para a criança surda. [...] No entanto, como a escrita alfabética mapeia os sons da fala, os erros da criança ouvinte são muito menos graves do que os da surda. [...] Como a criança surda não tem acesso aos sons da fala, esses não servem de auxílio à escrita (CAPOVILLA e CAPOVILLA, 2004, p.35).

Para os autores, é necessário reconhecer uma relevante falha que ameaça o sucesso na abordagem bilíngue, que é a falta de atenção à descontinuidade existente entre língua de sinais e escrita alfabética. Eles sugerem, como proposta para equacionar essa descontinuidade entre L1 e língua escrita de diferentes naturezas, a adoção da escrita visual direta de sinais antes da alfabetização em LP. Esta proposta é considerada por Capovilla e Capovilla (2004) e Quadros (2000) a ponte metalinguística para transpor o fosso entre LS e a escrita alfabética.

No presente estudo não abordamos a escrita de sinais na educação dos surdos, mas reconhecemos que a ponte metalinguística proposta por esses autores pode ser construída a partir do ensino precoce e consistente da LS 
aos surdos, e de atividades que os levem a refletir sobre língua e linguagem a partir das LS, para que, posteriormente, essa reflexão seja possível em LP.

\section{ANDAIMENTO COLETIVO}

Para Vygotsky (1988), a interação social é mediadora do processo de aquisição cognitiva geral que se dá através da linguagem. $\mathrm{Na}$ educação, portanto, o professor é o principal mediador da aprendizagem do aluno, facilitando-lhe o domínio e a apropriação dos diferentes instrumentos culturais. $\mathrm{O}$ autor considera que os processos psicológicos superiores não são inatos, mas originam-se nas relações entre indivíduos humanos e se desenvolvem ao longo do processo de internalização de formas culturais de comportamento (VYGOTSKY, 1988). Um dos conceitos-chave da teoria vygotskyana é o da ZDP (Zona de Desenvolvimento Proximal ou Potencial), em que o autor, mais uma vez, enfatiza a importância do papel do mediador, como o professor, por exemplo. Esta zona representa a potencialidade, ou seja, pode se constituir como lugar onde os conceitos espontâneos e já formulados pelo aprendiz se encontram com os conceitos científicos que lhe são apresentados.

Tomando como ponto de partida o conceito de ZDP, em que se entende que o aprendiz necessita de interação com outro mais capaz para, através do seu aprendizado, desenvolver-se além do que conseguiria sozinho, Wood, Bruner e Ross (1976), em um estudo sobre ensino-aprendizagem entre pais e filhos em idade pré-escolar, conceituam esse processo interativo como "andaimento" (scaffolding). Numa analogia com a construção civil, podemos exemplificar esse processo visualizando um mestre elevando o andaime à medida que o aprendiz vai conseguindo proficiência na aplicação de um conhecimento já consolidado. $\mathrm{O}$ artigo referido trata da natureza do processo de tutoria, ou seja, quando um adulto ou especialista ajuda alguém mais jovem ou menos especialista. Para verificar como isso ocorre, os autores examinaram as maiores implicações na relação de interação entre o desenvolvimento da criança e seu tutor, na aquisição das competências para resolver problemas. $\mathrm{O}$ objetivo era observar como a criança adquiria habilidades e podia, assim, resolver o problema proposto com a assistência do tutor, pois, para eles, a interação com o tutor envolvia muito mais do que simplesmente a imitação de um modelo. $\mathrm{O}$ processo de andaimento, então, habilitaria a criança ou novato a resolver um problema, realizar uma tarefa ou meta que estaria além de seus esforços se não houvesse a presença 
do tutor. Neste procedimento, o adulto (ou pessoa mais capacitada) controla inicialmente alguns elementos até o aprendiz ser capaz de completar a tarefa proposta, adquirindo, então, a competência para isso. Nas pesquisas sobre aquisição de línguas nessa mesma direção, observa-se, por exemplo, aprendizes que são capazes de realizar algumas tarefas na língua estrangeira, sozinhos, mas outras não (WOOD, BRUNER \& ROSS, 1976, p.90).

De maneira resumida, e para título de informação, listamos abaixo os seis passos do andaimento estabelecidos pelo estudo de Wood, Bruner e Ross (1976, p.98):

1. Recrutamento - a primeira e mais óbvia tarefa do tutor é chamar a atenção do aprendiz para que haja um engajamento deste a solucionar o problema;

2. Redução dos graus de dificuldade - o tutor deve reduzir os atos necessários para a execução da tarefa, ou seja, simplificá-lo em tarefas menores, para que o aprendiz dê um passo de cada vez e o tutor vá regulando o feedback, a resposta à sua ação.

3. Manutenção do direcionamento - apesar dessas subdivisóes da tarefa, o tutor deve convencer o aprendiz a sempre continuar para o próximo nível, pois a tendência é que ele regrida e limite suas capacidades. $\mathrm{O}$ tutor deve motivá-lo a seguir o objetivo principal da tarefa, para que o êxito que ele teve em fases anteriores não o distraia deste objetivo.

4. Sinalizar as características mais relevantes - o tutor deve destacar as características mais importantes da tarefa, mostrando a diferença entre o que o aprendiz produziu e o que ele acha que deveria ter feito, o que considera uma forma correta daquela produção, interpretando as discrepâncias existentes.

5. Controlar a frustração - o tutor deve entender que resolver o problema com sua ajuda deve ser menos estressante e perigoso do que sem a sua ajuda, portanto, ele deve proteger a face do aprendiz diante dos erros cometidos, incentivá-lo a tentar novamente e não supervalorizar o que tem pouca importância. Também deve tomar cuidado quanto ao risco de criar uma dependência muito grande no aprendiz.

6. Demonstração - o tutor deve oferecer uma demonstração ou um modelo para resolver a tarefa. Isso envolve uma idealização do que ele espera que seja feito e, neste processo, ele também estará fornecendo explicações sobre a realização da tarefa. $\mathrm{O}$ aprendiz, com o modelo, se sentirá compelido a tentar imitá-lo e resolver a tarefa da forma mais apropriada. 
A partir do modelo de andaimento desses investigadores, Donato (1994) realizou uma pesquisa sobre o mesmo tema: a realização de uma tarefa com a ajuda de um tutor (pessoa mais capacitada do que o aprendiz). Porém, seu trabalho pretendia observar as funçōes do tutor ao oferecer suporte para o aprendiz em trabalhos entre pares, ou seja, onde todos eram aprendizes.

Donato (1994) buscou identificar a presença da prática do andaimento nas interaçôes entre pares em sala de aula de língua francesa como segunda língua, com o objetivo de compreender como os alunos co-constroem experiências de língua no contexto de sala de aula. Assim, Donato (1994) pretendia descobrir como o desenvolvimento da L2 é trazido para o plano social, partindo da hipótese de que os aprendizes podem, de certa maneira, em algumas circunstâncias, prover o mesmo tipo de suporte e orientação uns aos outros, assim como os adultos fazem com as crianças. Para isso, ele observou um grupo de alunos do $3^{\circ}$ semestre de francês de uma universidade americana. O grupo estudado fazia parte de uma turma que realizava constantemente atividades em grupo e foi escolhido dentre outros por possuírem a maior unidade entre seus integrantes. Segundo o autor, o grupo trabalhava tão bem, buscando soluções para os problemas apresentados, que sua voz parecia a de um único falante (cf. DONATO,1994, p.40). Através de análise de protocolos, ele buscou traçar um quadro da co-construção da aprendizagem de língua desses alunos e de como se dá o desenvolvimento desta no plano social.

De forma semelhante, em nossa pesquisa, após a coleta e transcrição dos dados, foram selecionadas as interações em que os alunos surdos tentam resolver, em conjunto, a tarefa proposta: produzir uma carta de reclamação sobre a escola onde estudam, em língua portuguesa. Nosso objetivo era verificar como isso ocorre em grupos de estudantes usuários de línguas de sinais, durante a realização de tarefas onde haja a necessidade de utilização da língua portuguesa escrita, considerada sua segunda língua.

Para gerar os dados necessários à nossa pesquisa, elaboramos uma unidade didática composta por cinco oficinas em uma turma de sexta série do ensino fundamental de uma escola especial para surdos da rede estadual, na região metropolitana do Rio Grande do Sul, no início do ano letivo de 2008. A turma observada era composta por seis alunos, duas meninas e quatro meninos, com idade entre quatorze e dezessete anos, todos surdos profundos e usuários de LS.

A unidade didática propunha, ao seu término, que os alunos, em trios, produzissem uma carta de reclamação a um órgão responsável pela 
administração da escola, pedindo melhorias na infraestrutura e na qualidade de ensino desta. Para isto, as oficinas trabalhavam o gênero textual carta, com leituras e atividades de reconhecimento e manipulação de textos deste gênero, e atividades de concordância verbal de alguns verbos que pudessem ser utilizados na produção da carta. A escolha da concordância verbal em LP se deu por entendermos que ela é um elemento gerador de dificuldade para os aprendizes surdos, devido ao fato de, nas Línguas de Sinais, a concordância ocorrer de maneira distinta à LP. Quadros e Karnopp (2004) afirmam que nas LS a concordância é obrigatória com o objeto, podendo ou não ser realizada com o sujeito, dependendo da seleção do verbo.

\section{PARTICIPANTES DA PESQUISA}

Os participantes de nossa pesquisa eram, à época, alunos de uma escola especial de educação de surdos, fundada há mais de quarenta anos, que atendia alunos de todos os níveis do ensino básico (educação infantil, ensino fundamental e ensino médio). A escola atende exclusivamente alunos surdos, inclusive aqueles que apresentam outros tipos de deficiência além da surdez. Com todo o seu prédio adaptado, a comunicação entre alunos, professores e funcionários se dava majoritariamente em Libras. Para avisar sobre o início e término de cada período a escola possui campainhas sonoras e luminárias, com lâmpadas vermelhas que piscam durante o alerta da campainha. $\mathrm{Na}$ entrada da escola, também há um telefone público adaptado para deficientes auditivos. Na quadra de esportes da escola, algumas vezes antes das aulas, professores e alunos se reúnem para fazerem um alongamento, principalmente dos braços e mãos, preparando-se para as horas de intensa interação em LS que terão pela frente.

A turma da 6 a série do ensino fundamental onde a pesquisa foi realizada contava com 06 (seis) alunos: Thomas, Emanuelle, Ernesto, Ricardo, Hellen e Wiliam. Interessa-nos, neste artigo, caracterizar os três alunos cujas interações analisaremos aqui: Thomas, Emanuelle e Hellen. Thomas, de dezessete anos, é um aluno que veio de outra escola, também uma escola especial, localizada em uma cidade vizinha. Relatou que, anteriormente, havia estudado em uma escola regular, experiência que, segundo ele, não foi positiva. Emanuelle, de dezesseis anos, é uma das alunas mais fluentes em LS, e apesar de morar em um município distante da escola, estuda ali desde a $2^{\text {a }}$ série do ensino fundamental. Hellen, de quatorze anos, é a mais nova e a mais inquieta aluna da sala de aula. Geralmente está envolvida em brigas 
e confusões, possui uma pequena porcentagem de audição e também mora em uma cidade distante da escola.

As aulas de LP observadas geralmente levavam um certo tempo para se iniciarem, pois, como começavam logo após o período de recreio, os alunos chegavam à sala de aula aos poucos, depois que a professora já havia entrado. Também chegavam muito agitados, correndo, conversando muito ou brigando por algum desentendimento ocorrido durante o recreio, atrasando bastante o início das atividades propostas pela professora.

Os únicos materiais utilizados nas aulas de LP eram o caderno e o livro de LP, intitulado Novo Diálogo, distribuído pelo MEC, e desenvolvido para alunos ouvintes, cuja LP é a primeira língua. Algumas vezes, a atividade em aula era ler e copiar os textos contidos no livro. A biblioteca da escola estava sempre fechada, e o laboratório de informática estava obsoleto, segundo relato de professora e alunos. Não foi observado o uso de dicionários de LP em aula, nem de alguma outra literatura específica para este alunado.

\section{COMO OS DADOS FORAM PRODUZIDOS, TRANSCRITOS E ANALISADOS}

A observação de como se dá a construção de conhecimento entre os alunos surdos na disciplina de Língua Portuguesa foi realizada a partir de observações da interação entre estes em sala de aula. Vários trabalhos já foram realizados para descrever a organização em sala de aula, e como se dá o processo de aprendizagem através da interação (GABBIANI, 2005; GARCEZ, 2006).

Os dados foram coletados através de filmagens, fotografias, acesso aos textos produzidos pelos alunos e anotaçôes feitas pela pesquisadora a partir das observações durante as aulas. Após a coleta, os dados selecionados como pertinentes à realização desta pesquisa foram transcritos e analisados. Tratando-se de interaçôes que intercalam dois códigos linguísticos (a Libras e a LP), fez-se necessária a adoção de um sistema de transcrição apropriado para esse contexto, uma sala de aula envolvendo um professor ouvinte e seus alunos surdos, aprendizes de LP.

Em estudos feitos no Brasil, onde a utilização de sistemas de transcrição de LS foi necessária, encontramos basicamente dois tipos de sistemas: o Sistema de Transcrição em Sinais, exposto por Quadros e Karnopp (2004) e o Sistema de Notação em Palavras, desenvolvido e utilizado pela Federação Nacional de Educação e Integração de Surdos (FENEIS). Levando em 
conta alguns fatores, como a necessidade de um sistema simples e de fácil compreensão para não usuários de LS, este trabalho baseia-se na escolha adotada por Maria do Socorro Correia Lima (2004) em sua tese de doutorado. A autora explica que utilizou na pesquisa apenas uma parte do Sistema de Notação em Palavras, para efeito de simplificação, e também discorre que este se denomina assim porque as palavras de uma língua oral (no caso, Língua Portuguesa) serão utilizadas para representação aproximada dos sinais da Libras.

Portanto, segundo Lima (2004, p.113), a LS será representada a partir das seguintes convenções:

- Os sinais em Libras, para efeito de simplificação, serão representados por itens lexicais do português em letras maiúsculas. Exemplos: BRINCADEIRA, ESCOLA, SURDO.

- A datilologia (alfabeto manual), que é utilizada para expressar nome de pessoas, de localidades e outras palavras que não possuem um sinal específico, será representada pela palavra separada por hífen. Exemplos: E-S-C-O-V-A-R, M-I-S-S-Â-O.

- Para os sinais não manuais (expressões facial e corporal) que são realizados simultaneamente com um sinal, para simplificação, serão utilizadas, para a representação de frases nas formas exclamativas e interrogativas, os sinais de pontuação usados na escrita de línguas orais, ou seja: !, ? e !?.

- A língua oral, que é utilizada pelos sujeitos investigados (professora ouvinte, pesquisadora ouvinte, alunos surdos), será representada em letra minúscula e escrita em itálico.

- Os comentários explicativos feitos pela pesquisadora, que são utilizados no decorrer da transcrição tanto dos sinais como das falas, serão representados em letra minúscula entre parênteses.

- A pantomima9 será representada em letra maiúscula, escrita em negrito e em itálico.

- A mímica ${ }^{10}$ será representada em letra maiúscula, escrita em negrito.

\footnotetext{
${ }^{9}$ Representação de uma história exclusivamente através de gestos, expressões faciais e movimentos, especialmente no drama ou na dança; mímica. A arte de representar exclusivamente por meio de movimentos corporais (LIMA, 2004, p.114).

${ }^{10}$ A gesticulação que acompanha a fala oral (LIMA, 2004, p.114).
} 
- A tradução da língua de sinais feita pela pesquisadora será representada entre colchetes.

Ainda não há estudos que evidenciem se, nas línguas de sinais, existem desinências para gêneros (feminino e masculino) e número (plural), equivalentes à LP; portanto, o sinal, representado por palavra do português e que possui estas marcas, receberá o símbolo @ para demarcar a idéia de ausência e não causar confusão quanto a estes aspectos. Exemplos: meu@ (meu[s]e minha[s]), amig@ (amigo[s] e amiga[s]), fri@ (frio[s] e fria[s]). As marcas de plural podem ser visualizadas através da repetição do sinal, e a representação será feita por um sinal de mais $(+)$ localizado no lado direito do sinal que está sendo repetido. Exemplos: CASA+, ÍNDIO+.

Além do descrito acima, encontrado em Lima (2004), também foi necessário utilizarmos outras convenções de transcrição, emprestadas da Análise da Conversa e de trabalhos sobre análise da fala-em-interação. São os seguintes:

- Pausas maiores de três segundos serão transcritas com algarismos entre parênteses; por exemplo, uma pausa de quatro segundos será transcrita (0.4).

- Uma pausa menor de três segundos será transcrita apenas com um ponto final entre parênteses. Exemplo: (.). Tal diferenciação se torna relevante para nossa análise, por considerar que pausas muito longas são significativas na interação.

- Quando o que foi sinalizado em LS não for compreendido pela analista, será transcrito como $(\mathrm{xxx})$.

- Quando a fala oral não for compreendida será transcrita como (\#).

- Os verbos serão transcritos sempre no modo infinitivo.

Na gravação analisada, encontramos dois códigos linguísticos distintos: a Língua Portuguesa falada - utilizada pela professora e pela pesquisadora, ambas ouvintes, e por uma aluna surda que às vezes oraliza algumas palavras - e a Libras. Estes dois códigos possuem canais perceptuais diferentes, sendo, portanto, de modalidades diferentes. Quadros (2007) explica:

As línguas apresentam diferentes modalidades. Uma língua falada é oralauditiva, ou seja, utiliza a audição e a articulação através do aparelho vocal para compreender e produzir os sons que formam as palavras dessas 
línguas. Uma língua sinalizada é visual-espacial, ou seja, utiliza a visão e o espaço para compreender e produzir os sinais que formam as palavras nessas línguas (QUADROS, 2007, p.3).

Por utilizarem canais diferentes, elas podem ser produzidas simultaneamente, o que torna o processo de transcrição mais trabalhoso e extenso do que de uma sequência conversacional onde apenas uma modalidade de língua é utilizada (como em línguas orais-auditivas, por exemplo). Em nossa análise, quando ambas foram utilizadas simultaneamente pelo mesmo interlocutor, foi transcrito primeiramente o sinal, e, posteriormente, a fala oral.

No dia da gravação dos dados analisados a turma foi dividida em dois trios, denominados como Grupo 1 e Grupo 2 para fins de análise. Dois tipos de dados foram selecionados, transcritos e analisados: os textos produzidos pelos alunos, que serão transcritos mantendo as características físicas do mesmo, como tipo e tamanho da letra, pontuação e ortografia, e as sequências de interação entre os alunos do Grupo 1, que foram gravadas em vídeo e posteriormente transcritas de acordo com as convençóes explicitadas no item anterior.

Assim como o trabalho realizado por Donato (1994), as atenções da pesquisadora estão focalizadas em apenas um grupo dentro da turma de alunos selecionada. As duas câmeras de vídeo utilizadas foram posicionadas de modo a captar a interação ocorrida neste grupo.

A análise da interação entre os alunos foi feita a partir da comparação do texto produzido com as transcrições das sequências interacionais. Assim, será possível realizar o objetivo desta pesquisa ao observar como se deu a co-construção de conhecimento na produção conjunta da tarefa solicitada.

A turma, que neste dia contava com cinco alunos presentes em sala de aula (Wiliam havia faltado), se reuniu em dois grupos: Emanuelle, Thomas e Hellen (Grupo 1); Ricardo e Ernesto (Grupo 2). Neste trabalho, nossa análise será focalizada no primeiro grupo citado, devido a seu engajamento e a outros fatores já observados anteriormente, como o interesse nas atividades escolares, disposição para realizar as tarefas solicitadas e uma certa "harmonia" entre participantes do grupo. A seguir apresento a transcrição ${ }^{11}$

${ }^{11}$ No processo de transcrição do texto, todos os elementos considerados importantes para a análise foram mantidos: formatação da caligrafia (por vezes a escrita era em letra cursiva - aqui representada em letras maiúsculas e minúsculas - em outras, em letras de forma - todas em maiúsculas); distribuição das palavras nas linhas; pontuação; ortografia; acentuação; correções feitas pelos alunos em tachado duplo; margens do 
da carta ${ }^{12}$ produzida pelo Grupo 1:

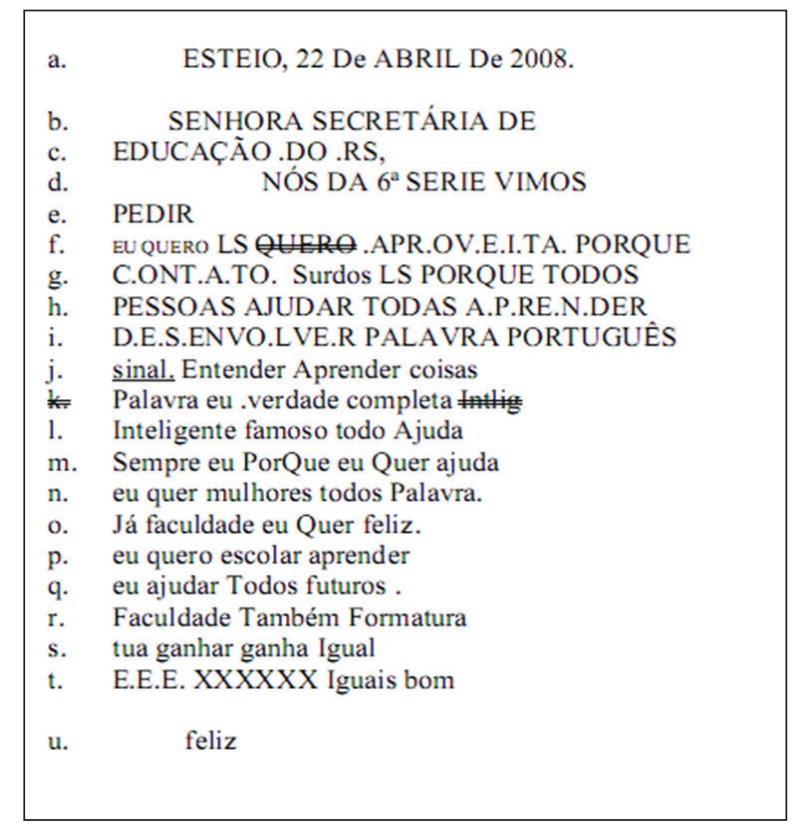

FIGURA 1 - Carta produzida pelo grupo 1

Fonte: PIRES, 2009, p. 96.

Durante a produção do texto, os alunos do Grupo 1 sentaram-se próximos. Hellen estava em uma carteira própria, de frente para Emanuelle e Thomas, que dividiam a mesma carteira (sentando-se um em frente ao outro), e os dois de lado para Hellen (conforme ilustrado na Figura 2, a seguir). Duas câmeras filmadoras (c1 e c2) foram posicionadas em direção aos participantes do grupo com o objetivo de registrarem com maior eficiência as interaçōes entre eles:

início de cada linha; sublinhado; palavras em tamanhos exageradamente menores. ${ }^{12}$ Para facilitar a análise do texto da carta, as linhas do mesmo foram organizadas em alíneas alfabéticas, já que as sequências conversacionais serão numeradas. 


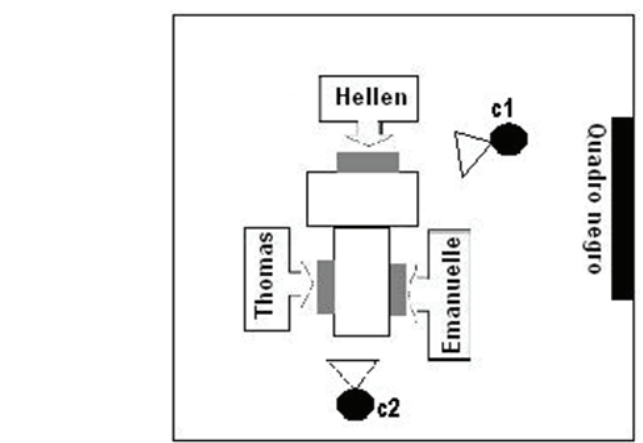

FIGURA 2 - Configuração espacial dos alunos do Grupo 1 Fonte: PIRES, 2009, p. 97.

Hellen se encarregou de escrever o texto que seria produzido, copiando as instruções dadas pela professora e sendo a primeira a chamar seus colegas para a produção do texto. Também é de Hellen a letra de toda a carta, exceto a assinatura de Emanuelle no final da produção. Algumas vezes, conversas paralelas aconteciam com o outro grupo, e em alguns momentos a professora interveio, solicitando que os alunos se voltassem para a realização da tarefa. Hellen, então, se voltava para Thomas, e Emanuelle parecia desinteressada em realizar a tarefa, ficando a maior parte do tempo sem participar da produção do texto. Hellen e Thomas também não solicitaram a sua atenção em nenhum momento, nem a autorização ou confirmação da colega sobre nenhuma construção textual, exceto quando tinham dúvidas a respeito de algum vocábulo em LP. Emanuelle permaneceu grande parte do tempo da realização da tarefa manipulando um aparelho de telefone celular.

\section{ANÁLISE DE DADOS}

Ao compararmos a gravação em vídeo e o texto produzido por Hellen e Thomas, observamos que o processo de produção da carta funciona basicamente assim: primeiramente, Thomas sinalizava em Libras para Hellen, que, em seguida, escrevia o que foi ditado por Thomas, processo este que demonstra a interferência da LS no texto escrito, inclusive a ausência de concordância verbal, como observamos no decorrer do texto. Entretanto, essa escrita não é direta, "automática", mas Hellen demonstra, em alguns momentos, ter noção desta interferência, e também o entendimento que o texto deve ser produzido em outro código linguístico, que possui suas próprias regras, como modalidade escrita da LP. 
O processo de andaimento coletivo entre os alunos pode ser observado já na sequência 1. A professora havia solicitado ao grupo que parasse de conversar sobre outros assuntos e iniciasse a tarefa de produção do texto imediatamente, visto que a hora avançava. Hellen, então, copiou do quadro negro o cabeçalho da carta já oferecido pela professora, enquanto Thomas e Emanuelle conversavam, esperando que a colega terminasse de copiar. Alguns instantes após terminar de copiar do quadro, ela se dirige a Thomas, e inicia a interação seguinte:

\section{SEQUÊNCIA 1}

Início da produção do texto

\begin{tabular}{|lll|}
\hline 01 & Hellen: & EU, POR EXEMPLO, EU QUERO LS (xxx) EU QUERO LS \\
02 & Thomas: & OK, SIM, PORQUE APROVEITA QUER CONTATO PORQUE \\
03 & Hellen: & ENTENDI (começa a escrever imediatamente) \\
04 & Thomas & (ao ver Hellen copiar, pára de sinalizar e espera que ela volte a \\
05 & & dar atenção a ele) L-S-QUERO \\
06 & Hellen & (olha para Thomas e escreve) \\
07 & Emanuelle: & (toca o braço de Thomas e chama a atenção dele) \\
\hline
\end{tabular}

Na sequência acima, Hellen ao ler as sugestôes dadas pela professora no quadro negro se identifica com o primeiro item e apresenta a proposta para Thomas, conforme a 1.01. Na 1.02, Thomas concorda com a sugestão da colega, e complementa a frase. Hellen sinaliza que entendeu a mensagem, e começa a escrever a carta, a partir do que é ditado por Thomas. Na 1.05 constatamos que é dele a construção do enunciado "LS quero", perfeitamente gramatical em Libras.

A segunda sequência que apresentaremos neste artigo, com o objetivo de analisarmos a negociação entre os participantes, é a sequência 3.

$\mathrm{Na}$ sequência 3, apresentada a seguir, observamos que nem tudo o que é ditado por Thomas para Hellen é aceito e escrito no texto por ela, diferente do que pode parecer em um primeiro momento. Observando mais atentamente a produção do texto, comparando com a interação dos participantes, verificamos que Hellen faz uma seleção do que é ditado pelo colega, e que, muitas vezes, ela espera receber toda a mensagem ditada por ele, para depois, então, traduzi-las para LP. 


\section{SEQUÊNCIA 3}

Ditado de Thomas para Hellen

\begin{tabular}{|lll|}
\hline 01 & Thomas & (puxa a folha que está diante de Hellen, chamando a atenção dela) \\
02 & Hellen: & (volta-se a Thomas. Olha a carta e começa a ler, sinalizando o \\
03 & & que já foi escrito para ele) LER (aponta o dedo para um ponto do \\
04 & & texto) EU QUERER LS (aponta novamente para o texto) \\
05 & & APROVEITAR PORQUE CONTATO (olha para Thomas) \\
06 & Thomas: & SURD@CONTATO \\
07 & Hellen: & (olha para Thomas e escreve) \\
08 & Thomas: & (espera Hellen terminar de copiar) \\
19 & Hellen: & (pára de escrever e olha para Thomas) \\
10 & Thomas: & SURD@LS CONTATO \\
11 & Hellen: & (olhando para o texto) JÁ já (aponta para um ponto do texto) \\
12 & Thomas: & CONTATO SURD@LS \\
13 & Hellen: & (escreve) \\
14 & Thomas: & CERTO. L-I-B-R-A-S \\
\hline
\end{tabular}

$\mathrm{Na}$ sequência 3, Hellen e Thomas continuam interagindo sem a participação de Emanuelle. Algumas vezes ela interagia com o grupo, como na linha 7 da Sequência 1, porém sua intervenção era para falar sobre outros assuntos, chamar a atenção para o telefone celular que carregava, ou para conversar sobre outros jovens. Nessas vezes, Thomas e Hellen acabavam se envolvendo na conversa com Emanuelle e deixando a atividade proposta de lado.

Em nenhum momento Thomas ou Hellen produziram o texto independentes, sempre houve a participação ou aceitação do outro. Por diversas vezes, um esperava que o outro terminasse a conversa com Emanuelle ou outra pessoa, para, juntos, voltarem à atividade. Na l.1, Thomas chama a atenção de Hellen para que esta, que estava dispersa observando a interação de Emanuelle com integrantes do outro grupo, volte para a tarefa solicitada. Ela prontamente volta-se para Thomas, e começa a ler para ele, sinalizando o texto, aquilo que já fora escrito até aquele momento. Ela também aponta para Thomas o trecho do texto que está sendo lido, possibilitando que ele acompanhe, e assim possa revisar ou alterar alguma coisa. Quando termina de ler a frase, ela faz uma pausa e olha para seu colega, passando o turno para ele. Thomas então segue ditando as palavras a serem escritas através de sinais e datilologia, sinalizando e parando, à medida que Hellen escreve o texto a ser ditado.

No entanto, em nenhum momento reivindicaram a participação de Emanuelle, nem reclamaram de sua abstenção na atividade, o que nos 
surpreendeu um pouco, já que, em muitos momentos observados por nós nas aulas de LP, esta era uma das alunas mais interessadas em realizar as tarefas solicitadas pela professora.

Grande parte da co-construção da tarefa realizada, neste caso, a produção de texto em segunda língua, se deu através de uma negociação que consistia em ambos aceitarem ou não o que estava sendo proposto pelo colega. Aqui, o termo negociação é utilizado para expressar as propostas apresentadas, aceitação e não aceitação dessas propostas na interação entre os participantes para realizar a tarefa solicitada. Thomas apresentava suas propostas em língua de sinais, ditando para Hellen o que devia ser escrito, e esta, por sua vez, aceitava (escrevendo) ou não aceitava (não escrevendo) o que estava sendo proposto. Na Tabela 1, elaborada para demonstrar melhor a negociação entre eles, podemos observar que Hellen também propunha alterações e correções do texto:

TABELA 1

Negociação e co-construção entre os participantes

\begin{tabular}{|c|c|c|}
\hline \multicolumn{3}{|l|}{ Sequîêricia 3} \\
\hline Apresentação & 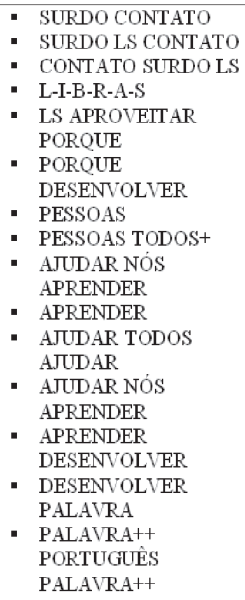 & Thomas \\
\hline Aceitação & $\begin{array}{ll}\text { - } & \text { CONTINUA } \\
: \text { ESPERA } \\
\text { - } \\
\text { DALMA } \\
\text { PALENVOLVIER } \\
\end{array}$ & Hellen \\
\hline Não aceitação & - JÁ já & Hellen \\
\hline Aceitação & - CERTO (7 vezes) & Thomas \\
\hline
\end{tabular}

Fonte: PIRES, 2009, p.107. 
A Tabela de Negociação procura representar, de maneira resumida e compacta, a interação que se deu entre Hellen e Thomas na produção do texto proposto. As interações em cinza foram produzidas por Hellen, e as em branco pertencem a Thomas. Procuramos selecionar os segmentos em: Apresentação - quando um dos dois apresenta ao colega uma proposta para o texto; Aceitação - quando o colega aceita o que foi proposto pelo companheiro; e Não aceitação - quando o que foi proposto não é aceito, seja para evitar uma repetição no texto ou por desconhecimento do vocábulo correspondente em LP (não aceitação imediata). Conforme pode ser observado na Tabela 1, várias eram as marcas que expressavam a aceitação ou a não aceitação do que fora proposto pelo colega. Hellen aparentemente aceitava o que era proposto por Thomas quando, imediatamente após a compreensão do que ele ditara, ela fazia anotaçóes no texto, e ele então esperava que ela escrevesse e o olhasse novamente para continuar ditando. Outro momento da interação em que Hellen não aceita imediatamente o que foi proposto é quando ela sinaliza e oraliza "jä", pois o que estava sendo ditado por Thomas já estava no texto. É possível observarmos, então, que Hellen analisa e seleciona o que vai ou não ser escrito no texto daquilo que Thomas dita. Essa seleção feita pela aluna, além da procura por uma compreensão total do enunciado que está sendo produzido por Thomas, para então traduzi-lo à modalidade escrita da LP, se caracteriza, segundo nosso entendimento, em uma importante estratégia de co-construção de conhecimento.

Reconhecemos que há outras ocorrências passíveis de análise na sequência selecionada, que esperamos realizar em outros estudos, tendo em vista o tamanho limitado de um artigo científico.

Segundo Donato (1994), no andaimento coletivo, mesmo que os aprendizes sejam inexperientes ou "novatos" individualmente, coletivamente se tornam "especialistas" no conhecimento necessário para realizar a tarefa solicitada, um orientando e guiando o outro na resolução de problemas linguísticos complexos, testando hipóteses e construindo coletivamente. Nos alunos observados aqui, verificamos que o texto produzido por eles em LP (tarefa solicitada) só é possível com a participação de ambos, e que Hellen e Thomas têm papéis que se completam na execução da tarefa. À Hellen cabe a função de analisar e selecionar o que é ditado por Thomas e traduzir isso, de Libras para LP escrita. Ela também faz suas próprias sugestôes e revisa o que já foi produzido, além de ir em busca da tradução de algumas palavras que não conhece ou não se recorda em LP. Thomas não se envolve com a escrita 
da carta, mas planeja o que vai ser abordado nela, produz os enunciados em Libras, procura dar sequência lógica e coesão a esses enunciados e também traduz para a LP alguns vocábulos.

A interação entre os alunos observados lhes possibilita que alcancem um nível mais profundo de seu desenvolvimento potencial, chegando além do que conseguiriam sozinhos, ou seja, nível de desenvolvimento real, segundo a teoria da ZDP. Esse desenvolvimento se realiza a partir de indivíduos que se identificam, como no caso de Hellen e Thomas.

\section{CONSIDERAÇÕES FINAIS}

A partir da transcrição dos dados registrados em vídeo durante a produção da carta pelos alunos Thomas e Hellen, uma análise da fala-eminteração desses dois interagentes foi reveladora para observarmos como ocorreu o processo de co-construção de aprendizagem de língua na classe de LP/S. Cada um dos dois assumiu um papel diferente para a produção da carta. Thomas sinalizava em Libras para Hellen as reivindicações a serem dirigidas à secretaria de educação estadual para a melhoria de sua escola, tecendo um discurso sobre a importância social e cognitiva da Libras neste contexto escolar; Hellen, por sua vez, era a responsável pela transcrição desta carta, tarefa não muito simples. Ela então traduzia de LS para LP escrita o que Thomas ditava, fazia seleção e uma espécie de resumo dessas ideias, evitando repetições e procurando tornar a mensagem mais clara e direta, demonstrando entender a diferença de um texto oralizado/sinalizado para um texto escrito. Quando desconhecia a forma correspondente em LP ela consultava a professora e/ ou a pesquisadora que estavam presentes na sala de aula no momento da produção.

A partir desse trabalho em conjunto, foi possível encontrar os seis passos do andaimento apontados por Wood, Bruner e Ross (1976), provando que é possível encontrarmos essa estratégia de aprendizagem no contexto estudado. Várias estratégias foram criadas por Thomas e Hellen para construir esse andaime mútuo: a negociação da produção do texto entre eles, com a apresentação de propostas de enunciados, aceitação ou não aceitação do colega foi um grande indício desta prática, encontrada durante a análise da transcrição de dados. Mesmo quando a proposta não era aceita pelo companheiro havia uma proteção da face deste, minimizando esta negação e evitando qualquer desarmonia entre os dois interagentes.

Outra característica do andaimento foi o constante incentivo que um dava ao outro para que ambos se mantivessem unidos na mesma tarefa, 
através de sinais como "OK", "CONTINUA", "CERTO". Também podese observar, comparando a transcrição do vídeo e o texto produzido, como Hellen selecionava o que era proposto para Thomas, fazendo sua própria construção a partir da interpretação do que era dito pelo colega e do que traduzia da LS para a LP escrita. Além disso, a aprendiz também revisava aquilo que já havia sido escrito, procurando realmente dar sentido àquele texto.

Assim, a co-construção de aprendizagem de língua, já estudada em outros cenários, pode ser verificada também em uma classe de língua portuguesa para aprendizes surdos usuários de LS como L1. A partir do entendimento de que é altamente produtiva uma co-construção de aprendizagem de LP entre os alunos surdos, partindo da dupla analisada, foi possível relacionar essa interação dos alunos com a internalização de regras da língua-alvo observada.

É importante pensar em atividades e estratégias aplicáveis ao contexto de ensino de LP/S que facilitem a aprendizagem desta disciplina, visto a escassez de materiais e estudos com este objetivo. Para este fim é necessária uma reflexão sobre um ambiente escolar bilíngue e bicultural, com a presença e valorização tanto da LS quanto da LP.

A LS permitirá o pleno desenvolvimento cognitivo da criança surda, não impedido pela presença da surdez, além de oportunizar que ela interaja socialmente e que receba informações e conceitos necessários para o seu crescimento e maturidade. Portanto, quanto mais cedo a criança surda for exposta à LS de sua comunidade, maior será o seu desenvolvimento. Como vimos, a maioria das crianças surdas nascem em lares ouvintes e seu primeiro contato com a LS se dará somente na escola. Em minha opinião, esse é mais um fator que aumenta a importância de uma escola de surdos preparada, qualificada e aberta à comunidade.

A LP, por outro lado, possibilita o acesso aos bens culturais (literatura, educação), informações através da mídia, preparação para o exercício da cidadania, podendo participar politicamente em uma sociedade onde tudo é expresso e regulamentado em LP. Como cidadão brasileiro, o surdo tem o direito de aprender essa língua com qualidade. Quando o conhecimento em LS for deficiente, haverá uma dificuldade maior para aprender a língua oral da sociedade em que está inserido.

Para que essa disciplina seja ofertada com qualidade precisa ser assumida como uma L2 do aluno surdo. Ou seja, ela precisa ser concebida de maneira semelhante a uma língua estrangeira, com metodologias e 
práticas específicas, professores especializados e material didático adequado a esse corpo de aprendizes, levando em consideração a Libras como sua L1, sua faixa etária e os objetivos deles de aprender a LP. Não me parece ideal também que sejam adotados livros didáticos para aprendizes estrangeiros, o que descaracterizaria o surdo como cidadão brasileiro. Apesar de possuir uma cultura surda, esta não o exclui da cultura brasileira, pois os surdos convivem e estão inseridos nela. O surdo está imerso na sociedade ouvinte brasileira e é rodeado de informaçôes e imagens próprias desta sociedade. Também me parece interessante adotar práticas que reconheçam o conhecimento linguístico e cultural que este aluno já possui para construir seu conhecimento em LP, assim como atividades de seu interesse.

As práticas de atividades em conjunto em LP já são conhecidas por todos. Porém, estudos como este mostram como elas podem ser frutíferas também no ensino de alunos surdos. Nos dados analisados pode-se encontrar diversas estratégias utilizadas por Hellen e Thomas, como maior engajamento na atividade, oferecimento de feedbacks ao colega, autocorreção e correção do colega, incentivo a continuar, oferta de exemplos, divisão de tarefas. Este artigo reforça, através destas conclusōes, a importância do conhecimento construído coletivamente, onde todos têm participação importante no processo de aprendizagem. Na proposta do andaimento coletivo, o suporte é construído por todos os envolvidos no processo, ao mesmo tempo em que todos são erguidos pelo andaime. O que cada um sabe é somado e esse conhecimento se dinamiza, soluciona problemas, constrói novas possibilidades coletivamente e confere mais autonomia a cada indivíduo.

\section{REFERÊNCIAS}

CAPOVILLA, F. C. Filosofias educacionais em relação ao surdo: do oralismo à comunicação total ao bilinguismo. Revista Brasileira de Educação Especial. Marilia, SP, v.6, n.1, p.99-116, 2000. CAPOVILLA, F.C.; CAPOVILLA, A. G. S. O desafio da descontinuidade entre a língua de sinais e a escrita alfabética na educação bilíngue do surdo congênito. In: RODRIGUES, C; TOMICH, L. M. et. al. Linguagem e cérebro humano: contribuiçôes multidisciplinares. Porto Alegre: Artes Médicas, 2004. p.19-51.

DONATO, R. Collective Scaffolding in Second Language Learning. In: LANTOLF, J.P; APPEL, G. (Org.). Vygotskian Approaches to Second Language Research. New Jersey: Norwood, 1994.

FERREIRA-BRITO, L. Similarities and Differences in Two Sign Languages. In: Sign Language Studies, n.42, p.45-46. Silver Spring: Linstok Press, 1984. 
GABBIANI, B. Escuela, lenguaje y poder. 2a .ed. Montevidéo: Departamento de publicaciones, Universidad de la República: 2005.

GARCEZ, P. M.; \& OSTERMANN, A. C. Glossário conciso de Sociolinguística Interacional. In: RIBEIRO B. T.; GARCEZ, P. M. (Org.). Sociolinguistica Interacional. São Paulo: Loyola, 2002. (2a. edição, revista e ampliada, p.257-264). GARCEZ, P. M. A organização da fala-em-interação na sala de aula: controle social, reprodução de conhecimento, construção conjunta de conhecimento. Calidoscópio, 4(1), 66-80. Unisinos, São Leopoldo, 2006. Disponível em: http://www.unisinos. br/publicacoes_cientificas/images/stories/Publicacoes/Calid_v4n1/art07_garcez. pdf

KARNOPP, L.B. Práticas de leitura e escrita em escolas de surdos. In: FERNANDES, E. (Org.). Surdez e Bilinguismo. Porto Alegre: Mediação, 2005 . p.65-80.

KARNOPP, L.B.; PEREIRA, M.C.C.P. Concepçōes de leitura e de escrita na educação de surdos. In: LODI; HARRISON; CAMPOS (Org.). Leitura e escrita no contexto da diversidade. $3^{\text {a }}$.ed. Porto Alegre: Editora Mediação, 2010.

KARNOPP, L. B.; PEREIRA, M. C. C.P. Concepções de leitura e escrita na educação de surdos. In: LODI, A.C.B.; MELO, A.D.B.; FERNANDES, E. (Org.). Letramento, bilinguismo e educação de surdos. Porto Alegre: Editora Mediação, 2012. p.125.

LACERDA, C.B.F.; LODI, A.C. B. A inclusão escolar bilíngue de alunos surdos: princípios, breve histórico e perspectivas. In: LODI, A.C. B e LACERDA, C.B.F. Uma escola duas línguas: letramento em língua portuguesa e língua de sinais nas etapas iniciais de escolarização. Porto Alegre: Editora Mediação, 2009. p.11-32.

LIMA, M. S. C. Surdez, bilinguismo, inclusão: entre o dito, o pretendido e o feito. 2004. 271 f. Tese (Doutorado em Linguística Aplicada) - Instituto de Estudos da Linguagem, Universidade Estadual de Campinas, Campinas, 2004.

LODI, A. C. B. A leitura como espaço discursivo de construção de sentidos: oficinas com surdos. Tese (Doutorado em Linguística Aplicada). - Programa de Estudos Pós-graduados em Linguística Aplicada e Estudos da Linguagem, Pontifícia Universidade Católica de São Paulo, São Paulo, 2004.

LODI, A. C. B. A leitura em segunda língua: práticas constitutivas da(s) subjetividade(s) de um grupo de surdos adultos. Cad. Cedes, Campinas, v.26, n.69, p.185-204, maio/ago. 2006.

LODI, A. C. B. Plurilinguismo e surdez: uma leitura bakhtiniana da história da educação dos surdos. Educação e Pesquisa, São Paulo, v.31, n.3, p.409-424, set/ dez 2005. Disponível em: www.scielo.br/pdf/ep/v31n3/a06v31n3.pdf . Acesso em: 29 jan. 2007. 
NASCIMENTO, G. R. P. do. Aspectos de organização de textos escritos por universitários surdos. 2008. 256p. Tese (Doutorado em Linguística) - Programa de Pós-graduação em Letras, Universidade Federal de Pernambuco, Recife, 2008. PIRES, V. O. D. Andaimento coletivo como prática de ensino-aprendizagem de língua portuguesa para surdos. 2009. 145 p. Dissertação (Mestrado em Linguística Aplicada) - Programa de Pós Graduação em Linguística Aplicada, Universidade do Vale dos Sinos, São Leopoldo, 2009.

QUADROS, R. M. Alfabetização e o ensino da língua de sinais. Textura, Canoas, n.3, 2000.

QUADROS, R. M.; KARNOPP, L. B. Lingua de sinais brasileira: estudos linguísticos. Porto Alegre: Artmed, 2004.

QUADROS, R. M. O tradutor e intérprete de língua brasileira de sinais e língua portuguesa. Secretaria de Educação Especial. Brasília: MEC/SEESP, 2007.

SILVA, M. P. M. A construção de sentidos na escrita do aluno surdo. São Paulo: Ed. Plexus, 2001.

SOARES, M. Letramento: um tema em três gêneros. Belo Horizonte: Autêntica, 2010.

SUTTON-SPENCE, R. Mouthings and Simultaneity in British Sign Language. In: VERMEERBERGEN, M.; LEESON, L.; CRASBORN, O. (Org.). Simultaneity in Signed Languages: Form and Function. Amsterdam: Benjamins, 2007.

VYGOTSKY, L; LURIA, A.; LEONTIEV, A. Linguagem, Desenvolvimento e Aprendizagem. São Paulo: Ícone, 1988.

VYGOTSKY, L. A formação social da mente. São Paulo: Martins Fontes, 1987.

VYGOTSKY, L. Pensamento e linguagem. São Paulo: Martins Fontes, 1988.

WOOD, D.; BRUNER, J.; ROOS, G. The role of tutoring in problem solving. Journal of Child Psychology, v.17, p.89-100, 1976.

Data de submissão: 28/02/2014. Data de aprovação: 09/06/2014. 
